\section{Measurements for Global Trade}

ay 20 is World Metrology Day, commemorating the anniversary of the signing of the Metre Convention in 1875 . This treaty provides the basis for a worldwide coherent measurement system that underpins scientific discovery and innovation, industrial manufacturing and international trade, as well as the improvement of the quality of life and the protection of the global environment.

The theme for World Metrology Day 2020 is Measurements for global trade. This theme was chosen to create awareness of the important role measurement plays in facilitating fair global trade, ensuring products meet standards and regulations, and satisfying customer quality expectations.

Across the world, national metrology institutes continually advance measurement science by developing and validating new measurement techniques at the necessary level of sophistication. The national metrology institutes participate in measurement comparisons coordinated by the Bureau International des Poids et Mesures (BIPM) to ensure the reliability of measurement results worldwide.

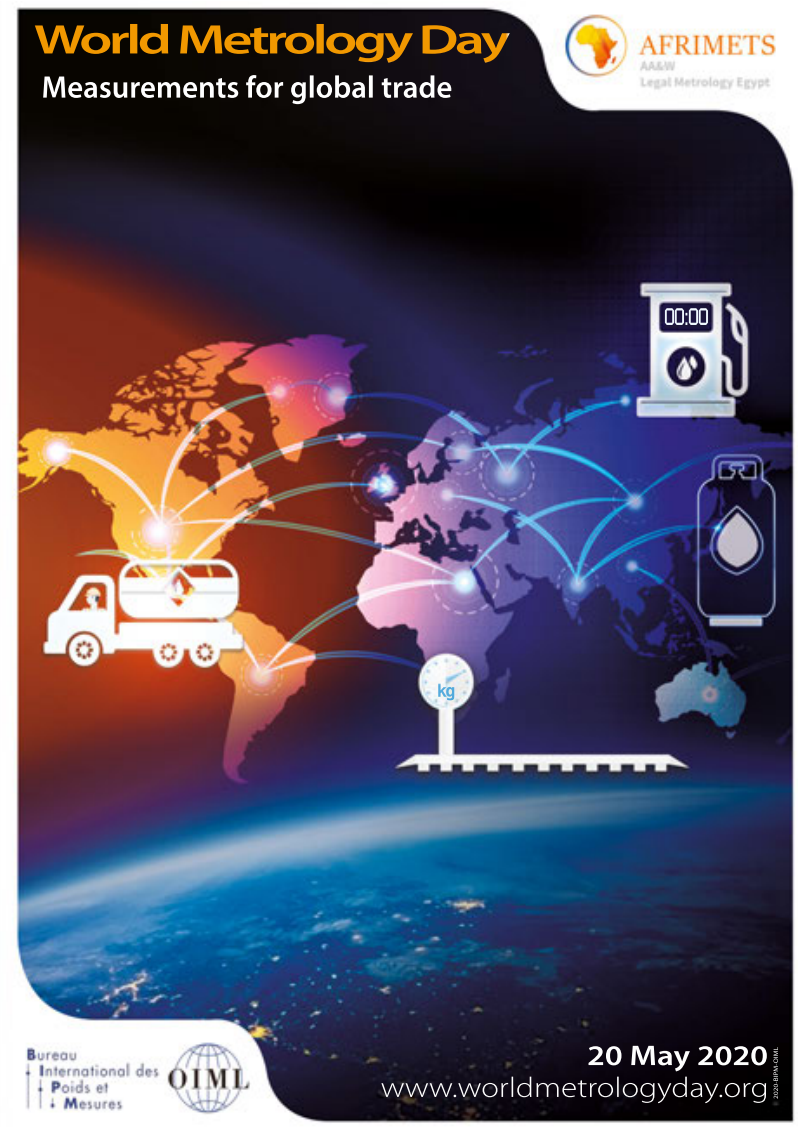

The International Organization of Legal Metrology (OIML) develops International Recommendations, which aim to align and harmonise requirements worldwide in many fields. The OIML also operates the OIML Certification System (OIML-CS) which facilitates international acceptance and global trade of regulated measuring instruments. These international metrology systems provide the necessary assurance and confidence that measurements are accurate, providing a sound basis for global trade today and helping us to prepare for the challenges of tomorrow.

The World Metrology Day project is realized jointly by the BIPM and the OIML; it is an annual event during which more than 80 countries celebrate the impact of measurement on our daily lives and recognise the contribution of all the people that work in intergovernmental and national metrology organisations and institutes throughout the year.

http://www.worldmetrologyday.org

\section{IYCN Celebrates Earth Day}

(n) gengage the next in so doing celebrate Earth Day, the International Younger Chemists' Network has launched a competition that seeks to recognise exemplary contributions to chemistry outreach. Applicants are invited to submit chemistry experiments that can be used

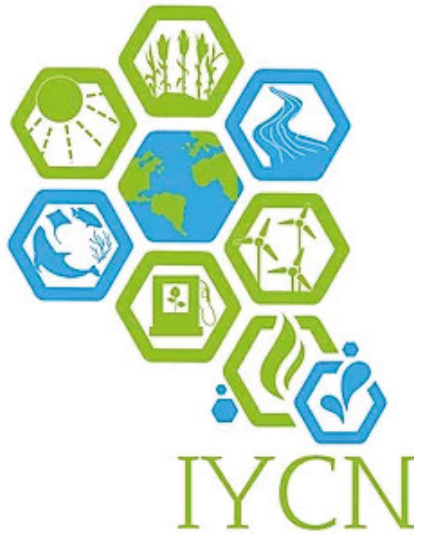
for outreach and public engagement under a specific theme. In honor of the 50th anniversary of Earth Day, the 2020 theme is Earth Chemistry.

The competition opened on 28 January 2020 in recognition of the oil spill that occurred in 1969 off the coast of Santa Barbara, California, which in part inspired the creation of Earth Day, and will close on Earth Day, 22 April 2020.

Experiments will be assessed according to their accessibility, repeatability, and suitability for the suggested audience. The winning submissions have the opportunity to publish their experiments in the IYCN experiment database.

https://iycnglobal.wixsite.com/competition 